This document is the unedited Author's version of a Submitted Work that was subsequently accepted for publication in 'The Journal of Physical Chemistry A', copyright () American Chemical Society after peer review. To access the final edited and published wo

https://pubs.acs.org/doi/abs/10.1021/jp0350722

\title{
A Theoretical Study on the Reactions of Hg with Halogens: Atmospheric Implications
}

\author{
Alexei F. Khalizov ${ }^{*}, \dagger$ Balakrishnan Viswanathan, ${ }^{\dagger}$ Pascal Larregaray,,$*$ and Parisa A. Ariya ${ }^{\dagger}$ \\ Electronic structure calculations were performed using DFT and high-level ab initio methods to \\ understand the role of atomic halogens in the transformation of gaseous mercury in the Arctic \\ atmosphere. The latter methods were found to be superior in reproducing the reaction enthalpies as well as \\ the geometrical parameters and vibrational frequencies, and therefore they were employed to calculate the \\ energy potentials for the capture- deactivation approach to study the kinetics of halogen-mercury atomic \\ recombination. Using the calculated rate constants and inferred concentrations of halogen atoms in the \\ Arctic troposphere, we found that atomic bromine might be responsible for the mercury depletion \\ episodes
}

\section{Introduction}

Mercury is mainly present in the atmosphere in its elemental form $(\mathrm{Hg}){ }^{1,2}$ Its lifetime is of the order of 1-2 years, which provides sufficient time for long-range transport, ${ }^{2}$ and explains the observation of nearly uniform mixing ratios of $\mathrm{Hg}$ within the Earth's atmosphere. ${ }^{2}$ High-temporal-resolution measurements of total gaseous mercury (TGM) in surface air at Alert, Canada, show that TGM concentrations exhibit a large variability in the spring upon the polar sunrise, with frequent episodes of exceedingly low values, ${ }^{3}$ which is most unexpected for a species with such a long lifetime. The variability of the mercury concentration is similar in form to the annual pattern of ozone depletion events that occur in the Arctic after the polar sunrise. ${ }^{4}$ Moreover, a good positive correlation between the measured concentrations of gaseous mercury and ozone has been observed at this site. ${ }^{3}$

The reactions of $\mathrm{Hg}$ with ozone $\mathrm{e}^{5-7}$ and molecular halogens ${ }^{8-10}$ are too slow to be a sink of tropospheric $\mathrm{Hg}$. Moreover, these reactions cannot account for the depletion events, as the latter are photochemical in nature, being only observed during the polar sunrise and not during the winter. Photoexcitation of both mercury and ozone can be ruled out since only light with $\lambda>300 \mathrm{~nm}$ penetrates the lower troposphere. At the same time, molecular halogens are readily photolyzed at these wavelengths producing halogen atoms, which play an important role in the depletion of ozone in the Arctic. ${ }^{11-16}$ Hence, it is very likely that mercury depletion events, having temporal concentration profiles similar to those of ozone, occur through a similar mechanism:

$$
\begin{gathered}
\mathrm{X}_{2}+h v \longrightarrow 2 \mathrm{X} \\
\mathrm{X}+\mathrm{O}_{3} \longrightarrow \mathrm{XO}+\mathrm{O}_{2} \\
\mathrm{Hg}+\mathrm{X} \longrightarrow \text { products } \\
\mathrm{Hg}+\mathrm{XO} \longrightarrow \text { products }
\end{gathered}
$$

To our knowledge, there is no data on the reactions of mercury with halogen oxides. An evaluation performed using the experimental formation enthalpies shows that the formation of mercury oxide, $\mathrm{HgO}$, and halogen atom, $\mathrm{X}$, in reaction 4 is a thermo-neutral or even moderately exothermic process (from

+0.5 to $-48.9 \mathrm{kJmol}^{-1}$, depending on the nature of $\mathrm{X}$ ). However, our theoretical computations ${ }^{17}$ characterize the above reaction as endothermic to the extent of more than $200 \mathrm{~kJ} \mathrm{~mol}^{-1}$, due to much lower calculated bonding energy in $\mathrm{HgO}$ as compared to experiment. Indeed, in a recent study, using large- scale multireference configuration interaction and coupled cluster calculations on $\mathrm{HgO}$, Shelper and Peterson ${ }^{18}$ concluded that gaseous $\mathrm{HgO}$ is significantly less stable than currently accepted, and hence it is unlikely that it can be formed directly from the oxidation of $\mathrm{Hg}$ by $\mathrm{BrO}$.

While the interaction with halogen atoms seems to be the only plausible process accounting for the fast mercury depletion in the atmosphere, the kinetic data on the reaction of mercury with atomic halogens is scarce. ${ }^{10,19}$ In the present work, using high-level DFT and ab initio computations, we performed an extensive study on the structures, vibrational frequencies, and relative energies of the reactants and products involved in the above reactions. Ab initio data were employed in evaluating the reaction rate constants to assess the direct contribution 
This document is the unedited Author's version of a Submitted Work that was subsequently accepted for publication in 'The Journal of Physical Chemistry A', copyright () American Chemical Society after peer review. To access the final edited and published wo

https://pubs.acs.org/doi/abs/10.1021/jp0350722

of atomic halogens to the depletion of mercury in the Arctic troposphere.

\section{Electronic Structure Calculations}

2.1. Computational Methods. Calculations were carried out using the Gaussian 98 (revision A.7) suite of programs. ${ }^{20}$ Owing to the large number of electrons and to account for relativistic effects, basis sets with inner electrons substituted by effective core potentials (ECP) were employed for Hg. The first basis set was LanL2DZ, which uses an all-electron description for the first-row elements (D95), and an ECP for inner electrons and double- $\$$ quality valence functions for the heavier elements. ${ }^{21-23}$ The second basis set employs the ECP60MWB pseudopotential of the Stuttgart/Bonn group ${ }^{24}$ with the MP2- optimized large uncontracted (9s9p6d4f) Gaussian-type (GTO) valence basis set of Schwerdtfeger and Wesendrup. ${ }^{25}$ This yields LanL2DZ and ECP60MWB(9s9p6d4f) basis sets for $\mathrm{Hg}$, denoted as $\mathrm{L} 2$ and E60, respectively. For elements $\mathrm{O}, \mathrm{F}, \mathrm{Cl}$, and $\mathrm{Br}$, we used LanL2DZ, 6-311G(2df), and (aug)-cc-pVNZ ( $) \mathrm{T}, \mathrm{Q}, 5,6)^{26-29}$ basis sets denoted as L2, G6, and (A)NZ, respectively. Geometry optimizations and frequency calculations were performed at the B3LYP and QCISD levels of theory. In the former case, the same basis set was used as for the desired energy calculation; in the latter case, L2\&G6 or E60\&G6 basis sets were employed for geometry optimization, and then, single- point energy was calculated at the $\operatorname{CCSD}(\mathrm{T})$ level using the desired basis set. In correlated ab initio calculations involving bromine, the $3 \mathrm{~d}$ orbital space was kept frozen.

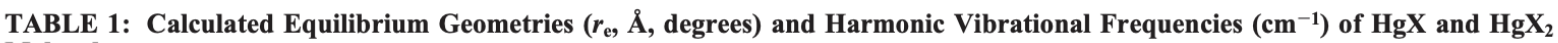
Molecules

\begin{tabular}{|c|c|c|c|c|c|c|}
\hline \multirow[b]{2}{*}{ species } & \multirow[b]{2}{*}{ property } & \multicolumn{4}{|c|}{ method/basis set } & \multirow{2}{*}{$\begin{array}{c}\text { experiment }^{a} \text { or } \\
\text { previous calculations }^{b}\end{array}$} \\
\hline & & B3LYP/L2 & B3LYP/E60\&AQZ & QCISD/L2\&G6 & QCISD/E60\&G6 & \\
\hline \multirow[t]{2}{*}{$\mathrm{HgF}$} & $r(\mathrm{Hg}-\mathrm{F})$ & 2.173 & 2.076 & 2.048 & 2.019 & $2.06-2.12^{c-e}$ \\
\hline & $\omega_{\mathrm{e}}$ & 390.3 & 414.7 & 486.2 & 493.2 & $490.8^{f}$ \\
\hline \multirow[t]{4}{*}{$\mathrm{HgF}_{2}$} & $r(\mathrm{Hg}-\mathrm{F})$ & 2.045 & 1.932 & 1.957 & & $\begin{array}{l}1.93^{g} \\
1.90-2.08^{c-e, g-j}\end{array}$ \\
\hline & $\Sigma_{\mathrm{g}}$ & 488.2 & 564.9 & 547.7 & & $567.6^{k}$ \\
\hline & $\Sigma_{\mathrm{u}}$ & 557.6 & 639.2 & 619.6 & & $640^{k}$ \\
\hline & $\Pi_{\mathrm{u}}$ & 82.2 & 173.8 & 144.4 & & $170^{k}$ \\
\hline \multirow[t]{2}{*}{$\mathrm{HgCl}$} & $r(\mathrm{Hg}-\mathrm{Cl})$ & 2.612 & 2.455 & 2.433 & 2.398 & $2.36-2.50^{c-e, l}$ \\
\hline & $\omega_{\mathrm{e}}$ & 228.9 & 240.0 & 278.2 & 278.3 & $292.6^{f}$ \\
\hline \multirow[t]{4}{*}{$\mathrm{HgCl}_{2}$} & $r(\mathrm{Hg}-\mathrm{Cl})$ & 2.442 & 2.285 & 2.311 & & $\begin{array}{c}2.33,{ }^{m} 2.252,{ }^{n} \\
2.25-2.44^{c-e, g, i, l, o}\end{array}$ \\
\hline & $\Sigma_{\mathrm{g}}$ & 287.7 & 338.2 & 328.0 & & $313,{ }^{p} 360^{q}$ \\
\hline & $\Sigma_{\mathrm{u}}$ & 345.1 & 391.9 & 376.8 & & $376, p 413^{q}$ \\
\hline & $\Pi_{\mathrm{u}}$ & 66.3 & 98.2 & 89.3 & & $100^{p}$ \\
\hline \multirow[t]{2}{*}{$\mathrm{HgBr}$} & $r(\mathrm{Hg}-\mathrm{Br})$ & 2.781 & 2.607 & 2.580 & 2.560 & $2.60^{c}$ \\
\hline & $\omega_{\mathrm{e}}$ & 141.3 & 152.7 & 180.1 & 173.4 & $186.5^{f}$ \\
\hline \multirow[t]{4}{*}{$\mathrm{HgBr}_{2}$} & $r(\mathrm{Hg}-\mathrm{Br})$ & 2.583 & 2.423 & 2.450 & & $\begin{array}{c}2.45,^{m} 2.41,^{p} \\
2.42-2.55^{c, g, i}\end{array}$ \\
\hline & $\Sigma_{\mathrm{g}}$ & 177.8 & 208.0 & 201.9 & & $195,^{p} 225^{q}$ \\
\hline & $\Sigma_{\mathrm{u}}^{\mathrm{g}}$ & 243.8 & 276.3 & 265.9 & & $271,^{p} 293^{q}$ \\
\hline & $\Pi_{\mathrm{u}}$ & 48.1 & 65.5 & 60.5 & & $90^{p}$ \\
\hline
\end{tabular}

${ }^{a}$ Experimental frequencies are fundamental, $\omega_{\mathrm{e}}$, radii are average, $r_{0} .{ }^{b}$ Results of theoretical calculations are given in italic. ${ }^{c}$ Ref $31 .{ }^{d}$ Ref 32 . ${ }^{e} \operatorname{Ref} 33 .{ }^{f} \operatorname{Ref} 40 .{ }^{g} \operatorname{Ref} 30 .{ }^{h} \operatorname{Ref} 34 .{ }^{i} \operatorname{Ref} 35 .{ }^{j} \operatorname{Ref} 36 .{ }^{k} \operatorname{Ref} 56 .{ }^{l} \operatorname{Ref} 37 .{ }^{m} \operatorname{Ref} 57 .{ }^{n} \operatorname{Ref} 39 .{ }^{o} \operatorname{Ref} 38 .{ }^{p} \operatorname{Ref} 58 .{ }^{q} \operatorname{Ref} 59$.

2.2. Results and Discussion. The reaction of mercury with atomic halogens is known to form $\mathrm{HgX}$ intermediates, ${ }^{19}$ which may self-react or interact with other atmospheric species. Under atmospheric conditions the self-reaction is too slow to be significant due to the low concentration of $\mathrm{HgX}$. Hence, only reactions with other species, e.g., halogen atoms, were considered in this study:

$$
\begin{aligned}
\mathrm{Hg}+\mathrm{X} & \rightarrow \mathrm{HgX} \\
\mathrm{HgX}+\mathrm{X} & \rightarrow \mathrm{HgX}_{2}
\end{aligned}
$$

For consistency, the reaction of mercury with molecular halogens was also included:

$$
\mathrm{H}+\mathrm{X}_{2} \rightarrow \mathrm{HgX}_{2}
$$

The optimized geometries and vibrational frequencies for the $\mathrm{HgX}$ and $\mathrm{HgX}$ species are presented in Table 1; inter-bond angles are not included because the molecules' equilibrium geometries are always linear. Experimental geometries are available only for mercury dihalides $\mathrm{HgCl}_{2}$ and $\mathrm{HgBr}_{2}$; in the case of $\mathrm{HgF}_{2}$, the bond length is an estimation made by $\mathrm{Cundari}^{30}$ using covalent atomic radii and electronegativities. There 
This document is the unedited Author's version of a Submitted Work that was subsequently accepted for publication in 'The Journal of Physical Chemistry A', copyright () American Chemical Society after peer review. To access the final edited and published wo

https://pubs.acs.org/doi/abs/10.1021/jp0350722

are no experimental bond lengths for $\mathrm{HgX}$; however, the vibrational frequencies are available. At the same time, a number of theoretical studies report both the geometries and vibrational frequencies of $\mathrm{HgX}$ and $\mathrm{HgX} 2$ species calculated at different levels of theory. ${ }^{30-38}$ Table 1 shows, where experimental data exist, that in our calculations B3LYP with small LanL2DZ basis set for mercury and halogens overestimated the bond lengths by 0.1 to $0.2 \AA$ and underestimated the vibrational frequencies by 40 to $100 \mathrm{~cm}^{-1}$. Employing larger basis sets, ECP60MWB- (9s9p6d4f) for mercury and aug-cc-pVQZ for halogens, resulted in significantly more accurate bond lengths. Frequencies were well reproduced for closed-shell molecules while for openshell species they were underestimated by 35 to $75 \mathrm{~cm}^{-1}$. Further extending the basis set for halogens up to aug-cc-pV5Z did not lead to a noticeable change in bond lengths.

Calculations at the QCISD level of theory using either the LanL2DZ or the ECP60MWB(9s9p6d4f) basis set for mercury resulted in quite accurate bond lengths and vibrational frequencies (Table 1); however, for the closed-shell molecules, the latter were better reproduced at the B3LYP level with extended basis set. Using a more extended basis set rather than the moderate 6-311G(2df) in QCISD calculations could have improved the results, but it was too computationally expensive.

Calculated reaction enthalpies $\Delta_{\mathrm{r}} H_{\text {calc }}{ }^{298}$ are presented in Table 2 as deviations from "experimental" values, $\Delta_{\mathrm{r}} H_{\exp }{ }^{298}$; the latter were derived from the tabulated experimental enthalpies of formation, $\Delta_{\mathrm{f}} H_{\exp }{ }^{298}$, of the corresponding gaseous species. ${ }^{39,40}$ Calculated total energies of halogen atoms were corrected to account for spin-orbit (SO) coupling using experimental spectroscopic data, ${ }^{40}-1.61,-3.52$, and $14.70 \mathrm{~kJ} \mathrm{~mol}^{-1}$, for fluorine, chlorine, and bromine atoms, respectively. In the case of the diatomic radicals $\mathrm{HgX}$, represented by the nondegenerate $\mathrm{X}^{2} \Sigma$ state, the $\mathrm{SO}$ effect is zero, ${ }^{41}$ the $\mathrm{SO}$ effect is also zero for $\mathrm{HgX}_{2}$ molecules because they are closed shell systems. Results of previous theoretical calculations $\mathrm{s}^{31,32,36-}$ 38 are also presented in Table 2 for comparison purposes. These calculations have been performed at different levels of theory ranging from DFT to high-level correlated ab initio, however, in most cases moderate basis sets were employed that led to very high deviation of calculated energies from experiment. Similarly, in our calculations, B3LYP with the moderate LanL2DZ basis set reproduced reactions 3 and 6 enthalpies with a maximum error of $26 \mathrm{~kJ} \mathrm{~mol}^{-1}$, while for recombination of $\mathrm{HgX}$ and X a deviation as large as $83 \mathrm{~kJ} \mathrm{~mol}^{-1}$ was observed. Apparently, the employed method was unable to recover the change in correlation energy for a nonisogyric ${ }^{42}$ process represented by reaction 5, leading to poor results. The dissociation energies of molecular halogens were also significantly underestimated. Modifying eq 5 to conserve spin, i.e.,

$$
\mathrm{HgX}+\mathrm{X}_{2} \longrightarrow \mathrm{HgX}_{2}+\mathrm{X}
$$

TABLE 2: Reaction Enthalpies $\left(\mathrm{kJ} \mathrm{mol}^{-1}\right)$ Calculated at Different Levels of Theory; Spin-Orbit Correction for Halogen Atoms Is Included

\begin{tabular}{|c|c|c|c|c|c|c|}
\hline \multirow[b]{2}{*}{ reaction } & \multirow[b]{2}{*}{ experiment $^{a}$} & \multicolumn{5}{|c|}{ deviation from experiment $\left(\Delta_{\mathrm{r}} H^{298}\right.$ calc $\left.-\Delta_{\mathrm{r}} H^{298}{ }_{\text {exp }}\right)$} \\
\hline & & $\begin{array}{l}\text { previous } \\
\text { calculations }\end{array}$ & $\begin{array}{l}\text { B3LYP/ } \\
\text { L2 }\end{array}$ & $\begin{array}{c}\text { B3LYP/ } \\
\text { E60\&AQZ }\end{array}$ & $\begin{array}{c}\mathrm{CCSD}(\mathrm{T}) / \mathrm{L} 2 \& \mathrm{G} 6 / / \\
\mathrm{QCISD} / \mathrm{L} 2 \& \mathrm{G} 6\end{array}$ & $\begin{array}{l}\text { CCSD(T)/E60\&A5Z// } \\
\text { QCISD/E60\&G6 }\end{array}$ \\
\hline $\mathrm{Hg}+\mathrm{F} \rightarrow \mathrm{HgF}$ & -137.84 & $\begin{array}{l}-64.9^{b},^{b} 46.0,^{c} \\
-65.2^{d}\end{array}$ & -16.9 & 0.2 & 30.1 & $1.0\left(9.5^{e}\right)$ \\
\hline $\begin{array}{l}\mathrm{HgF}+\mathrm{F} \rightarrow \mathrm{HgF}_{2} \\
\mathrm{Hg}+\mathrm{F}_{2} \rightarrow \mathrm{HgF}_{2}\end{array}$ & $\begin{array}{l}-375.97 \\
-355.03\end{array}$ & $12.1,{ }^{f}-5.7^{g}$ & $\begin{array}{r}61.2 \\
1.1\end{array}$ & $\begin{array}{r}4.9 \\
-3.8\end{array}$ & $\begin{array}{r}-1.1 \\
12.8\end{array}$ & \\
\hline $\mathrm{Hg}+\mathrm{Cl} \rightarrow \mathrm{HgCl}$ & -104.23 & $\begin{array}{l}-25.2,^{b} 33.9,^{h} \\
46.3^{c}-24.7^{d}\end{array}$ & -5.6 & 15.0 & 24.9 & $6.9\left(-0.6^{e}\right)$ \\
\hline $\begin{array}{l}\mathrm{HgCl}+\mathrm{Cl} \rightarrow \mathrm{HgCl}_{2} \\
\mathrm{Hg}+\mathrm{Cl}_{2} \rightarrow \mathrm{HgCl}_{2}\end{array}$ & $\begin{array}{l}-346.05 \\
-207.67\end{array}$ & $42.7,{ }^{f} 75.4^{i}$ & $\begin{array}{r}85.4 \\
-21.5\end{array}$ & $\begin{array}{l}32.5 \\
27.2\end{array}$ & $\begin{array}{l}15.3 \\
14.4\end{array}$ & \\
\hline $\begin{array}{l}\mathrm{Hg}+\mathrm{Br} \rightarrow \mathrm{HgBr} \\
\mathrm{HgBr}+\mathrm{Br} \rightarrow \mathrm{HgBr}_{2} \\
\mathrm{Hg}+\mathrm{Br}_{2} \rightarrow \mathrm{HgBr}_{2}\end{array}$ & $\begin{array}{r}-69.06 \\
-301.50 \\
-177.74\end{array}$ & $-30.4^{b}$ & $\begin{array}{r}-28.9 \\
61.0 \\
-1.1\end{array}$ & $\begin{array}{r}9.2 \\
31.1 \\
27.1\end{array}$ & $\begin{array}{l}20.1 \\
18.4 \\
14.7\end{array}$ & $6.3\left(0.8^{e}\right)$ \\
\hline $\begin{array}{c}{ }^{a} \operatorname{Ref} 40 \cdot{ }^{b}{ }^{b D F} \cdot{ }^{31}{ }^{c} \\
\operatorname{CSD}(\mathrm{T}) \cdot{ }^{36}{ }^{h} \mathrm{CCI}^{37}{ }^{i}\end{array}$ & $\begin{array}{l}\mathrm{PP}-\mathrm{MP} 2 .^{32} \\
\text { I. }^{38}\end{array}$ & A. ${ }^{32}{ }^{e}$ Calculatec & sing extra & ion formula & $=A+B \exp (-C L) \cdot{ }^{42}$ & ${ }^{f} \mathrm{BDF}-\mathrm{R} .{ }^{36}{ }^{g} \mathrm{QRPP}-$ \\
\hline
\end{tabular}


This document is the unedited Author's version of a Submitted Work that was subsequently accepted for publication in 'The Journal of Physical Chemistry A', copyright () American Chemical Society after peer review. To access the final edited and published wo

https://pubs.acs.org/doi/abs/10.1021/jp0350722 and using the experimental atomization energy of $\mathrm{X}_{2}\left(158.78,242.60\right.$, and $192.81 \mathrm{~kJ} \mathrm{~mol}^{-1}$ for $\mathrm{F}_{2}, \mathrm{Cl}_{2}$, and $\left.\mathrm{Br}_{2}\right),{ }^{40}$ reduced the enthalpy deviations to $-17.1,25.0$, and $-23.4 \mathrm{~kJ} \mathrm{~mol}^{-1}$, for the reactions involving $\mathrm{F}, \mathrm{Cl}$, and $\mathrm{Br}$, respectively. Using B3LYP with the ECP60MWB(9s9p6d4f) basis setformercury and aug-cc-pVQZ for halogens significantly reduced the error in reaction 5 enthalpies, but had little effect on the enthalpies of reactions 3 and 6. Extending the basis set for halogens to aug-cc-pV5Z did not lead to a noticeable improvement in the reaction enthalpies, indicating that basis set convergence limit at this level of theory has been reached. Uneven performance of B3LYP has been reported in a recent study ${ }^{43}$ on $\mathrm{Hg} / \mathrm{H}_{2} \mathrm{O}$ complexes where the quality of the results depended on whether the complex was neutral or cationic as well as on the geometry of the complex. Authors ${ }^{43}$ mention that, in some cases, B3LYP geometries were intermediate between MP2 and QCISD, being closer to QCISD while in other cases they rather agreed with MP2 results. Thus, overall, the B3LYP method cannot be judged to be performing well, though it might be considered as an alternative to high-level ab initio methods in certain cases.

As Table 2 shows, high-level CCSD(T)//QCISD calculations with moderate LanL2DZ and 6-311G(2df) basis sets for mercury and halogens, respectively, only slightly improved the reaction energies, suggesting that a more extended basis set needs to be used. Therefore, we investigated how the deviation in reaction 3 energy depends on the quality of the basis set employing ECP60MWB(9s9p6d4f) for mercury and (aug)-cc$\mathrm{pVNZ}(N) 3$ to 6) for halogens. Extending the basis set for halogens, while keeping LanL2DZ for $\mathrm{Hg}$, diverged the bonding energy away from experimental value. At the same time, as Figure 1 shows, using the ECP60MWB(9s9p6d4f) basis set for $\mathrm{Hg}$ in a similar calculation converged the bonding energy to a value close to experiment. As can be seen, using a basis set for halogens as large as aug-cc-pV5Z is necessary to reproduce the atomization energy of $\mathrm{HgX}$ to an absolute error less than $10 \mathrm{~kJ} \mathrm{~mol}^{-1}$. A combination of E60 with A5Z is reasonably well balanced: 5.6 electrons per primitive for $\mathrm{Hg}$ and 12.4 electrons per primitive for $\mathrm{Br}$, while in a similar combination of $\mathrm{L} 2$ with $\mathrm{A} 5 \mathrm{Z}$ there are only 2.5 electrons per primitive for $\mathrm{Hg}$ and the resulting basis set is unbalanced. Extending the basis set for $\mathrm{Hg}$, for example, to ECP60MWB(11s10p9d4f), ${ }^{44}$ is expected to lead to more accurate results, but it would also make the calculation more computationally expensive. Extrapolation of the type $E(L)$

) $A+B \exp (-C L)$, where $L) 3,4,5,6,{ }^{42}$ led to $9.7,0.3$, and $1.9 \mathrm{~kJ} \mathrm{~mol}^{-1}$ deviations at the infinite basis set limit in atomization energies for $\mathrm{HgF}, \mathrm{HgCl}$, and $\mathrm{HgBr}$, respectively. The results of these highlevel ab initio calculations were then used in the evaluation of rate constants for the reaction of mercury with halogen atoms (vide infra). 
This document is the unedited Author's version of a Submitted Work that was subsequently accepted for publication in 'The Journal of Physical Chemistry A', copyright ( $)$ American Chemical Society after peer review. To access the final edited and published wo

https://pubs.acs.org/doi/abs/10.1021/jp0350722

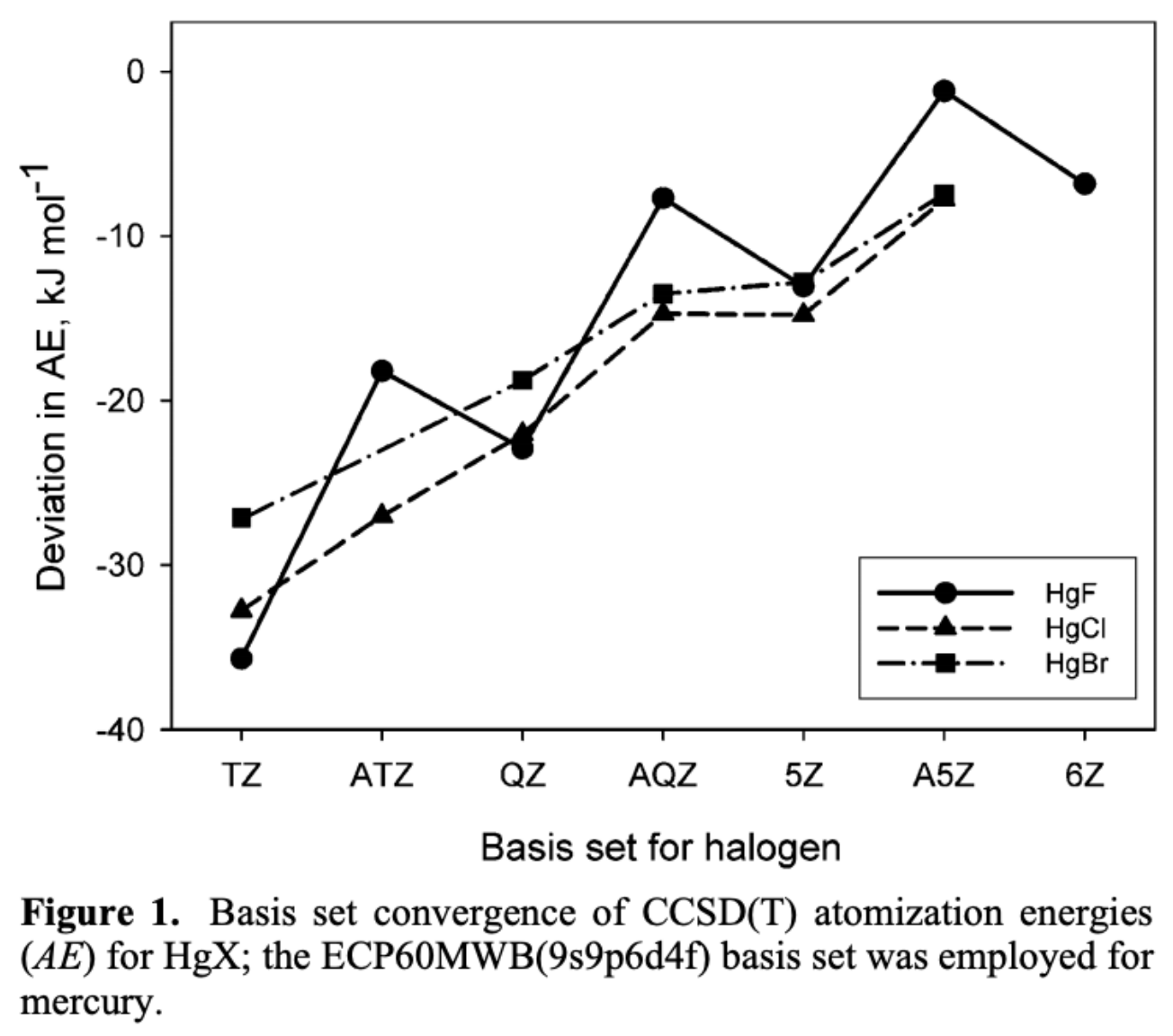

\section{Kinetics of Halogen - Mercury Atomic Recombination}

3.1. Theoretical Models. Rate constant calculations were performed for the recombination of $\mathrm{Hg}$ and $\mathrm{X}$ considering the following sequence of elementary steps:

$$
\begin{aligned}
\mathrm{Hg}+\mathrm{X} & \longrightarrow \mathrm{HgX}^{*} \\
\mathrm{HgX} & +\mathrm{M} \longrightarrow \mathrm{HgX}+\mathrm{M}
\end{aligned}
$$

The first step (reaction 8) accounts for the formation of the diatomic molecule $\mathrm{HgX}^{*}$ from the separated atomic reactants. This molecule is primarily formed in an unbound excited vibrational state and may either be stabilized by a collision with a molecule of the bath gas $(\mathrm{M})$ or dissociate back to the atomic reactants. If the pressure is high, the deactivation mechanism (reaction 9) is extremely fast and the overall rate constant for recombination equals the rate constant for the first step. Conversely, if the bath gas pressure is low, the collisional deactivation mechanism may play an important role.

First, the high-pressure limit rate constants for the recombination of $\mathrm{Hg}$ and $\mathrm{X}$ were evaluated using collision theory; ${ }^{45}$ then they were compared to the results of the Canonical Variational Transition State Theory (CVTST). ${ }^{46}$

The collision theory, based on the Langevin capture model, ${ }^{47,48}$ defines the transition state (TS) at a given energy $E$ with respect to the bottom of the reactant channel, by the position of the top of the centrifugal barrier. This effective potential barrier, created by an exact compensation of the centrifugal repulsive force and the attractive interaction force, is characterized by $r^{\mathrm{q}}$, its position along the reaction coordinate, and $L_{\max }$, the maximum value of the angular momentum compatible with the energy, through the two following 
This document is the unedited Author's version of a Submitted Work that was subsequently accepted for publication in 'The Journal of Physical Chemistry A', copyright (C) American Chemical Society after peer review. To access the final edited and published wo

https://pubs.acs.org/doi/abs/10.1021/jp0350722

conditions:

$$
\begin{aligned}
\mathrm{V}\left(\mathrm{r}^{\neq}, \mathrm{L}_{\text {max }}\right)= & \frac{\mathrm{L}_{\text {max }}^{2}}{2 \mu \mathrm{r}^{\neq 2}}+\mathrm{V}\left(\mathrm{r}^{\neq}\right)=\mathrm{E} \\
& \left.\frac{\partial \mathrm{V}\left(\mathrm{r}, \mathrm{L}_{\text {max }}\right)}{\partial \mathrm{r}}\right|_{\mathrm{r}^{\neq}}=0
\end{aligned}
$$

Where $\mu$ is the diatomic molecule reduced mass, $r$ is the interatomic distance, and $V(r)$ is the potential describing the interaction between the two atoms. The capture cross section $\sigma(E)$ is then calculated by

$$
\sigma(E)=\pi b_{\max }^{2}
$$

where $b_{\max }$, the maximal impact parameter, is related to $L_{\max }$ by

$$
b_{\max }=\frac{L_{\max }}{\sqrt{2 \mu E}}
$$

The high-pressure limit canonical rate constant is recovered by averaging the energy-resolved capture cross section over the relative kinetic energy distribution at a given temperature $T$,

$$
k_{\text {inf }}(T)=\frac{1}{k_{B} T}\left(\frac{8}{\pi \mu k_{B} T}\right)^{\frac{1}{2}} \int_{0}^{\infty} E \sigma(E) e^{-k_{B} T} d E
$$

where $k_{\mathrm{B}}$ is the Boltzmann constant.

For the calculation of the CVTST rate constant, the equilibrium constant $K_{\text {eq }}$ and the high-pressure limit for the rate of unimolecular decomposition $k^{\mathrm{CVT}}(T)$ were first evaluated and then the rate constant for recombination was evaluated. The unimolecular rate constant, $k^{\mathrm{CVT}}(T)$, is calculated at a fixed temperature by minimizing the generalized rate constant, $k^{\mathrm{GT}}(T, r)$, with respect to $r$, which defines the dividing surface. ${ }^{46}$

The deactivation process (reaction 9) was treated by a simple model similar to the one developed by Bunker, ${ }^{49}$ within the framework of the capture model. The vibrationally excited diatomic molecule, $\mathrm{HgX} *$, is supposed to be stabilized if it collides with a bath gas molecule during its lifetime. At given energy $E$ and angular momentum $L$, this lifetime is approximated by one period of vibration, which is defined by

$$
\tau(E, L)=2 \int_{r^{-}}^{r^{*}}\left\{\frac{2}{\mu}\left(E-\frac{L^{2}}{2 \mu r^{2}}-V(r)\right)\right\}^{\frac{-1}{2}} d r
$$

where $r^{\mathrm{q}}$ is the position of the transition TS (see eq 10), and $r^{-}$is determined by the integrand condition of existence. The range between $r^{q}$ and $r^{-}$defines arbitrarily the configuration domain for which $\mathrm{HgX}^{*}$ is considered as a molecular entity able to be stabilized. For $r>r^{\mathrm{q}}, \mathrm{Hg}$ and $\mathrm{X}$ are considered as separated atoms. The average lifetime for a given energy $\mathrm{E}$ is then given by

$$
\tau(E)=\frac{1}{L_{\max }} \int_{0}^{L_{\max }} \tau(E, L) d L
$$

The collision frequency $Z$ of $\mathrm{HgX} *$ with the bath gas molecules (here $\mathrm{N}_{2}$ and $\mathrm{O}_{2}$ ) is approximated by

$$
Z=0.8 Z_{N_{2}}+0.2 Z_{O_{2}}
$$

where $Z_{\mathrm{N}_{2}}$ or $Z_{\mathrm{O}_{2}}$ are, respectively, the collision frequencies of $\mathrm{HgX} *$ with $\mathrm{N}_{2}$ and $\mathrm{O}_{2}$. This average takes into account the chemical composition of the bath gas. For a given pressure $\mathrm{P}$ and temperature $T, Z_{\mathrm{O}_{2}}$ and $Z_{\mathrm{N}_{2}}$ are estimated, within the framework of the hard-sphere collision model. ${ }^{50}$ In this calculation, the overall size $d$ of 
This document is the unedited Author's version of a Submitted Work that was subsequently accepted for publication in 'The Journal of Physical Chemistry A', copyright () American Chemical Society after peer review. To access the final edited and published wo

https://pubs.acs.org/doi/abs/10.1021/jp0350722

each molecule, determined by adding the bond length $r_{\mathrm{e}}$ and the van der Waals radii $r_{\mathrm{vdw}}$ of each atom forming the molecule, is considered. The parameters used are summarized in Table 3. given by

Thus, for a given energy $E$, the deactivation probability $P(E)$ for an excited diatomic molecule $\mathrm{HgX} *$ is

$$
P(E)=Z \tau(E)
$$

In this simple model, each collision leads to deactivation and the maximum value of $P(E)$ is one. Then, the capture cross section taking into account deactivation, $\sigma_{\mathrm{de}}(E)$, at energy $E$ is now given by

$$
\sigma_{d e}(E)=\pi b_{\max }^{2} P(E)
$$

The corresponding pressure-dependent thermal rate constant $k_{\mathrm{P}}(T)$ is recovered by averaging the previous capture cross section $\sigma_{\mathrm{de}}(E)$ over the relative kinetic energy distribution, i.e., using eq 13 with $\sigma_{\mathrm{de}}(E)$ instead of $\sigma(E)$.

TABLE 3: Atomic and Molecular Parameters Used in the Rate Constant Calculations

\begin{tabular}{clc}
\hline atom & \multicolumn{2}{c}{$r_{\mathrm{vdw}}{ }^{a}, \AA$} \\
\hline $\mathrm{F}$ & 1.47 \\
$\mathrm{Cl}$ & 1.75 \\
$\mathrm{Br}$ & 1.85 \\
$\mathrm{~N}$ & 1.55 \\
$\mathrm{O}$ & \multicolumn{2}{c}{1.52} \\
$\mathrm{Hg}$ & 1.55 \\
\hline molecule & \multicolumn{2}{c}{$d, \AA$} \\
$\mathrm{HgF}$ & $r_{e}, \AA$ & 5.068 \\
$\mathrm{HgCl}$ & 2.048 & 5.733 \\
$\mathrm{HgBr}$ & 2.433 & 5.980 \\
$\mathrm{~N}_{2}$ & 2.580 & 4.2 \\
$\mathrm{O}_{2}$ & 1.1 & 4.2
\end{tabular}

${ }^{a} \operatorname{Ref} 60$.

\subsection{Calculating Rate Constants and Their Implications.}

Table 4 presents the calculated high-pressure limit rate constants $k_{\text {inf }}(T)$ and the pressure-dependent thermal rate constants $k_{\mathrm{P}}(T)$ for the recombination of atomic halogens with mercury. The Morse function was used in the collision theory and VTST calculations to describe the $\mathrm{Hg}-\mathrm{X}$ interaction potential. The function parameters were obtained by fitting eq 19 to the $\mathrm{Hg}-\mathrm{X}$ energies at different separations calculated at the $\operatorname{CCSD}(\mathrm{T}) /$ E60\&AQZ level of theory:

$$
V(r)=D_{e}\left\{1-\exp \left(-\beta\left(r-r_{e}\right)\right)\right\}^{2}
$$


This document is the unedited Author's version of a Submitted Work that was subsequently accepted for publication in 'The Journal of Physical Chemistry A', copyright () American Chemical Society after peer review. To access the final edited and published wo

https://pubs.acs.org/doi/abs/10.1021/jp0350722

TABLE 4: Comparison of Calculated and Experimental Dissociation Energies $\left(\mathrm{kJ} \mathrm{mol}^{-1}\right)$ for $\mathrm{HgX}$

\begin{tabular}{lrrrrr}
\hline & \multicolumn{2}{c}{$D_{\mathrm{e}}$} & & \multicolumn{2}{c}{$D_{0}{ }^{0}$} \\
\cline { 2 - 2 } \cline { 5 - 5 } species & this work & & this work $^{a}$ & Gaydon $^{b}$ & Huber and Herzberg \\
\hline $\mathrm{HgF}$ & 136.65 & & 133.74 & 133.89 & 173.61 \\
$\mathrm{HgCl}$ & 96.45 & & 94.79 & 96.23 & 96.45 \\
$\mathrm{HgBr}$ & 61.62 & 60.53 & 67.52 & 68.48
\end{tabular}

${ }^{a} D_{0}{ }^{0}=D_{\mathrm{e}}-\mathrm{ZPE}(\mathrm{HgX}) .{ }^{b} \operatorname{Ref} 51 .{ }^{c} \operatorname{Ref} 52$.

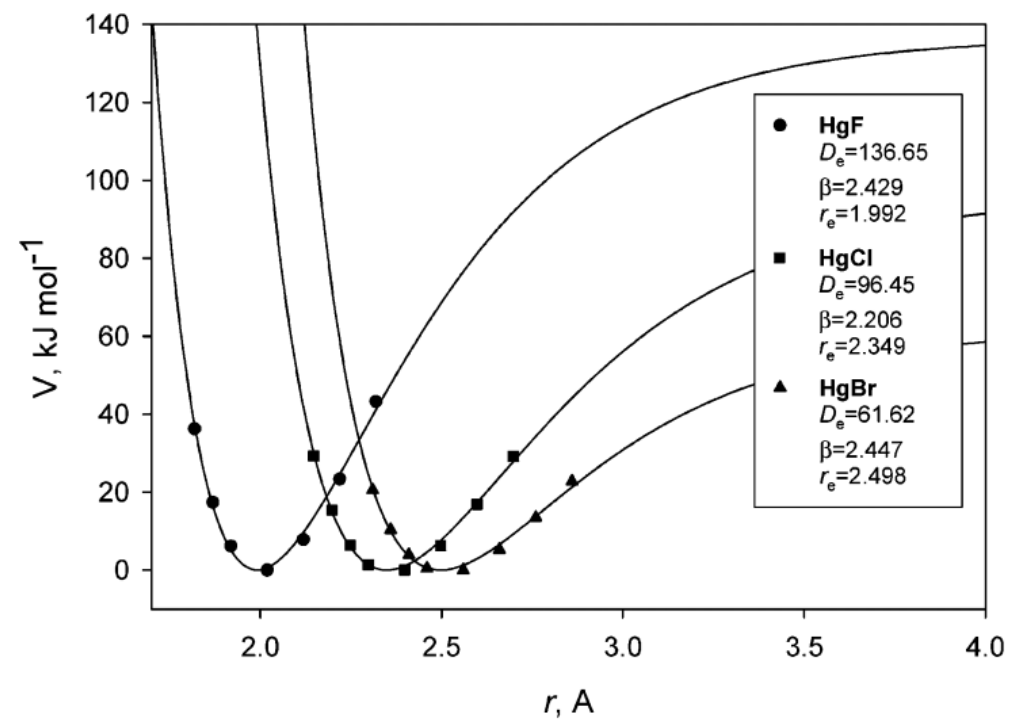

Figure 2. $\mathrm{HgX}$ energy potentials calculated at the $\operatorname{CCSD}(\mathrm{T}) /$ MWB60ECP\&AV5Z theory level. Lines were plotted by fitting Morse function to the ab initio data; a spin-orbit correction was applied to the dissociation energy.

where $D_{\mathrm{e}}$ is the dissociation energy $\left(\mathrm{kJ} \mathrm{mol}^{-1}\right), r_{\mathrm{e}}$ is the equilibrium bond distance $(\AA)$, and parameter $\S$ is $\left(\AA^{-1}\right)$. Figure 2 displays the calculated fits to the high-level ab initio data as well as the corresponding Morse parameters. The procedure involved keeping $D_{\mathrm{e}}$ constant while varying $r_{\mathrm{e}}$ and $\xi$ to obtain the best fit to the ab initio data. One can see that at intermediate separations between $\mathrm{Hg}$ and $\mathrm{X}$, explicit treatment of spin-orbit coupling for each point on the ab initio interaction potential would be necessary. Indeed, upon complete dissociation, the $\mathrm{HgX}$ radical, having $\mathrm{X}{ }^{2} \Sigma^{+}$electronic state, is transformed into atoms $\mathrm{Hg}$ and $\mathrm{Br}$ represented by ${ }^{1} S_{0}$ and ${ }^{2} P_{3 / 2}$ terms, respectively. Correspondingly, the $\mathrm{SO}$ contribution to the interaction potential due to the $\mathrm{Hg}$...X complex changes from zero at equilibrium, since $\operatorname{HgX}\left(\mathrm{X}^{2} \Sigma^{+}\right)$is nondegenerate, ${ }^{41}$ to $-1.61,-3.52$, or

$-14.70 \mathrm{~kJ} \mathrm{~mol}^{-1}$ for halogen atom, at infinite separation between $\mathrm{Hg}$ and $\mathrm{X}$. Around the equilibrium geometry at $r-r_{\mathrm{e}}<0.5 \AA$, the $\mathrm{Hg} . . . \mathrm{X}$ collision complex resembles the $\mathrm{HgX}$ moiety rather than the separate atoms $\mathrm{Hg}$ and $\mathrm{X}$. Thus, only the energies at moderate separations were used in the fitting procedure when it was safe to assume that the $\mathrm{X}^{2} \Sigma^{+}$electronic state for the $\mathrm{Hg}$...X complex is preserved and the SO effect is zero. At the same time, the dissociation energies of $\mathrm{HgX}$ were corrected for the spin-orbit coupling due to halogen atoms. Table 4 compares the calculated dissociation energies used in eq 19 with the available experimental values from Gaydon ${ }^{51}$ and Huber and Herzberg. ${ }^{52}$ These experimental data are very close to each other except for HgF where Herzberg's value ${ }^{52}$ is $0.4 \mathrm{eV}$ higher and listed as having high uncertainty. It should be noted, however, that changing the dissociation energy slightly would not substantially affect the kinetic data. The high-pressure rate constant depends only on the part of the potential between infinity and the top of the centrifugal barrier. This part is not expected to change 
This document is the unedited Author's version of a Submitted Work that was subsequently accepted for publication in 'The Journal of Physical Chemistry A', copyright () American Chemical Society after peer review. To access the final edited and published wo

https://pubs.acs.org/doi/abs/10.1021/jp0350722

significantly with a slight change in the dissociation energy; it would only affect the lifetime calculated by eq 14 , but not in a radical way.

Using two different approaches, CVTST and the capture model, resulted in consistent values of the highpressure-limit rate constants, though, for a given $T$, the CVTST rate constant was greater than the rate constant calculated using the capture model. This is not surprising since in the transition state theory, the better the TS is defined, the lower is the calculated rate constant. ${ }^{53}$ In the former theory the TS is defined as the best canonical average dividing surface, whereas in the latter it is defined in a more rigorous way, for each energy.

Table 5 shows that the calculated pressure-dependent rate constant $k_{\mathrm{p}}$ for the reaction of mercury with chlorine atoms is below the available experimental values, $1.5 \times 10^{-11}$ and $1.0 \times 10^{-11} \mathrm{~cm}^{3}$ molecule ${ }^{-1} \mathrm{~s}^{-1}$, within factors of 5.3 and 3.6. The experimental data were obtained using time-resolved ${ }^{19}$ and relative rate ${ }^{10}$ techniques, respectively. At the same time, $k_{\mathrm{p}}$ for the reaction of mercury with atomic bromine is very close to the recent experimental value, $3.2 \times 10^{-12} \mathrm{~cm}^{3}$ molecule ${ }^{-1} \mathrm{~s}^{-1}$. ${ }^{10}$ Since $k_{\mathrm{p}}$ revealed a weak negative temperature dependence, quite typical for a simple atomic recombination, one may expect the reaction to accelerate slightly in the Arctic troposphere, where the temperature is known to drop to about $233 \pm 10 \mathrm{~K}$ in the springtime.

The results of the present model for deactivation, where each collision is supposed to deactivate the unbound excited vibrational state, could certainly be improved by incorporating a collision efficiency factor. ${ }^{54}$ Nevertheless, such an improvement is not expected to change the calculated rate constants significantly. As a consequence, the simple model proposed here captures the main features of diatomic recombination kinetics and leads to a consistent comparison with experiments.

One can see that the reactions of $\mathrm{Hg}$ with atomic halogens are considerably fast, and it is very likely that they, with the exception of the reaction with atomic fluorine whose concentration in the troposphere is negligibly low, may contribute to the chemistry of mercury in the gas phase. We evaluated the lifetime of $\mathrm{Hg}$ due to loss reactions with chlorine and bromine atoms to be almost two years and half a day respectively, assuming $\mathrm{Cl}$ and $\mathrm{Br}$ steady-state concentrations to be $10^{4}$ and $10^{7}$ atom $\mathrm{cm}^{-3} .11,55$ Hence, despite the fast rate coefficient of the Cl-atom- initiated reaction of mercury, the inferred concentration of chlorine atoms is far too low to play a significant role. Atomic bromine, however, is present in a high enough concentration to completely destroy mercury within a short period of time, as observed in the Arctic. Nevertheless, further research is needed to assess the contribution from other active species such as halogen oxides to draw a complete picture of the mercury chemistry in the troposphere.

TABLE 5: Calculated Kinetic Parameters for Recombination of Halogen Atoms with Mercury

\begin{tabular}{|c|c|c|c|c|c|}
\hline \multirow[b]{2}{*}{ reaction } & \multirow{2}{*}{$\frac{\text { VTST }}{k_{\text {inf }}(298 \mathrm{~K}) \times 10^{10}}}$, & \multicolumn{4}{|c|}{ collision theory } \\
\hline & & $\begin{array}{l}Z(1 \mathrm{~atm}, 298 \mathrm{~K}) \\
\quad \times 10^{-9}, \mathrm{~s}^{-1}\end{array}$ & $\begin{array}{l}k_{\text {inf }}(298 \mathrm{~K}) \times 10^{10}, \\
\mathrm{~cm}^{3} \text { molecule s } \mathrm{s}^{-1}\end{array}$ & $\begin{array}{c}k_{\mathrm{p}}(1 \mathrm{~atm}, 298 \mathrm{~K}) \\
\times 10^{12}, \mathrm{~cm}^{3} \text { molecule s} \\
-1\end{array}$ & $\begin{array}{c}k_{\mathrm{p}}(1 \text { atm }, T) \\
\mathrm{cm}^{3} \text { molecule s }\end{array}$ \\
\hline $\mathrm{Hg}+\mathrm{F} \rightarrow \mathrm{HgF}$ & 4.69 & 8.24 & 4.29 & 1.86 & $0.92 \times 10^{-12} \exp (206.81 / T)$ \\
\hline $\mathrm{Hg}+\mathrm{Cl} \rightarrow \mathrm{HgCl}$ & 4.32 & 9.41 & 3.93 & 2.81 & $1.38 \times 10^{-12} \exp (208.02 / T)$ \\
\hline $\mathrm{Hg}+\mathrm{Br} \rightarrow \mathrm{HgBr}$ & 2.75 & 9.52 & 2.33 & 2.07 & $1.01 \times 10^{-12} \exp (209.03 / T)$ \\
\hline
\end{tabular}

\section{Acknowledgment.}

We acknowledge financial support from NSERC (National Science and Engineering Research Council of Canada), Environment Canada, $\mathrm{C}^{2} \mathrm{GCR}$ (the Centre for Climate and Global Change Research, McGill University). We thank the Centre for Research in Molecular Modeling (CERMM) at Concordia University for computer time. A.F.K. acknowledges NSERC/NATO Postdoctoral Science Program for financial support. P.L. acknowledges the Centre for Research in Molecular Modeling (CERMM), Concordia University, and the Fonds pour la Formation des Chercheurs et l'Aide a la recherche (FCAR), for providing his postdoctoral financial support.

\section{References and Notes}

(1) Lindberg, S. E.; Stratton, W. J. EnViron. Sci. Technol. 1998, 32,49.

(2) Schroeder, W. H.; Yarwood, G.; Niki, H. Water, Air, Soil Pollut.1991, 56, 653.

(3) Schroeder, W. H.; Anlauf, K. G.; Barrie, L. A.; Lu, J. Y.; Steffen, A.; Schneeberger, D. R.; Berg, T. Nature 1998, $394,331$. 
This document is the unedited Author's version of a Submitted Work that was subsequently accepted for publication in 'The Journal of Physical Chemistry A', copyright (C) American Chemical Society after peer review. To access the final edited and published wo

https://pubs.acs.org/doi/abs/10.1021/jp0350722

(4) Schroeder, W. H.; Barrie, L. A. IGAC Newsletter 1998, 7.

(5) Tokos, J. J. S.; Hall, B.; Calhoun, J. A.; Prestbo, E. M. Atmos. EnViron. 1998, 32, 823.

(6) P'yankov, V. A. Zh. Obsch. Khim. (Russ. J. Gen. Chem.) 1949,19, 224.

(7) Hall, B. Water, Air, Soil Pollut. 1995, 80, 301.

(8) Skare, I.; Johansson, R. Chemosphere 1992, 24, 1633.

(9) Medhekar, A. K.; Rokni, M.; Trainor, D. W.; Jacob, J. H. Chem. Phys. Lett. 1979, 65, 600

(10) Ariya, P. A.; Khalizov, A.; Gidas, A. J. Phys. Chem. A 2002, 106, 7310.

(11) Ariya, P. A.; Jobson, B. T.; Sander, R.; Niki, H.; Harris, G. W.; Hopper, J. F.; Anlauf, K. G. J. Geophys. Res. 1998, $103,13169$.

(12) Barrie, L.; Platt, U. Tellus, Ser. B 1997, 49B, 450.

(13) Langendorfer, U.; Lehrer, E.; Wagenbach, D.; Platt, U. J. Atmos. Chem. 1999, 34, 39.

(14) Martinez, M.; Arnold, T.; Perner, D. Ann. Geophys. 1999, 17,941.

(15) Mueller, R.; Crutzen, P. J.; Grooss, J.-U.; Bruehl, C.; Russell, J. M., III.; Tuck, A. F. J. Geophys. Res. 1996, 101, 12531.

(16) Ramacher, B.; Rudolph, J.; Koppmann, R. J. Geophys. Res. 1999,104, 3633.

(17) Khalizov, A.; Viswanathan, B.; Ariya, P. A. Unpublished data.

(18) Shepler, B. C.; Peterson, K. A. J. Phys. Chem. A 2003, 107, 1783.

(19) Horne, D. G.; Gosavi, R.; Strausz, O. P. J. Chem. Phys. 1968, 48.

(20) Frisch, M. J.; Trucks, G. W.; Schlegel, H. B.; Scuseria, G. E.; Robb,M. A.; Cheeseman, J. R.; Zakrzewski, V. G.; Montgomery, J. A., Jr.; Stratmann, R. E.; Burant, J. C.; Dapprich, S.; Millam, J. M.; Daniels, A. D.; Kudin, K. N.; Strain, M. C.; Farkas, O.; Tomasi, J.; Barone V.; Cossi, M.; Cammi, R.; Mennucci, B.; Pomelli, C.; Adamo, C.; Clifford, S.; Ochterski, J.; Petersson, G. A.; Ayala, P. Y.; Cui, Q.; Morokuma, K.; Malick,D. K.; Rabuck, A. D.; Raghavachari, K.; Foresman, J. B.; Cioslowski, J.; Ortiz, J. V.; Baboul, A. G.; Stefanov, B B.; Liu, G.; Liashenko, A.; Piskorz, P.; Komaromi, I.; Gomperts, R.; Martin, R. L.; Fox, D. J.; Keith, T.; Al- Laham, M. A.; Peng, C. Y.; Nanayakkara, A.; Gonzalez, C.; Challacombe, M.; Gill, P. M. W.; Johnson, B.; Chen, W.; Wong, M. W.; Andres, J. L.; Gonzalez, C.; Head-Gordon, M.; Replogle, E. S.; Pople, J. A. Gaussian 98, Revision A.7; Gaussian, Inc.: Pittsburgh, PA, 1998.

(21) Hay, P. J.; Wadt, W. R. J. Chem. Phys. 1985, 82, 270.

(22) Hay, P. J.; Wadt, W. R. J. Chem. Phys. 1985, 82, 299.

(23) Wadt, W. R.; Hay, P. J. J. Chem. Phys. 1985, 82, 284.

(24) Andrae, D.; Haeussermann, U.; Dolg, M.; Stoll, H.; Preuss, H.Theor. Chim. Acta 1990, 77, 123.

(25) Schwerdtfeger, P.; Wesendrup, R. http://www.theochem.uni-stut- tgart.de/pseudopotentials/index.en.html, 1999.

(26) Dunning, T. H., Jr. J. Chem. Phys. 1989, 90, 1007.

(27) Woon, D. E.; Dunning, T. H., Jr. J. Chem. Phys. 1993, 98, 1358.

(28) Wilson, A. K.; Woon, D. E.; Peterson, K. A.; Dunning, T. H., Jr.J. Chem. Phys. 1999, 110, 7667.

(29) Wilson, A.; van Mourik, T.; Dunning, T. H., Jr. THEOCHEM 1997,388, 339.

(30) Cundari, T. R.; Yoshikawa, A. J. Comput. Chem. 1998, 19, 902.

(31) Liao, M.-S.; Zhang, Q.-E.; Schwarz, W. H. E. Inorg. Chem. 1995,34, 5597. 233 .

(33) Kaupp, M.; Vonschnering, H. G. Inorg. Chem. 1994, 33, 4179.

(34) Kaupp, M.; Dolg, M.; Stoll, H.; Vonschnering, H. G. Inorg. Chem. 1994, 33, 2122.

(35) Kaupp, M.; Vonschnering, H. G. Inorg. Chem. 1994, 33, 2555.

(36) Liu, W.; Franke, R.; Dolg, M. Chem. Phys. Lett. 1999, 302, 231.

(37) Stroemberg, D.; Stroemberg, A.; Wahlgren, U. Water, Air, Soil Pollut. 1991, 56, 681.

(38) Stroemberg, D.; Gropen, O.; Wahlgren, U. Chem. Phys. 1989, 133, 207.

(39) Lide, D. R. CRC Handbook of Chemistry and Physics, 81st ed.; CRC Press: Boca Raton, FL, 2000.

(40) Chase, M. W., Jr. J. Phys. Chem. Ref. Data 1998, Monograph 9,1.

(41) Herzberg, G. Molecular Spectra and Molecular Structure. 1. Spectra of Diatomic Molecules, 2nd ed.; Van Nostrand Reinhold Company: Toronto, 1950.

(42) Jensen, F. Introduction to Computational Chemistry; John Wiley \& Sons: New York, 1999.

(43) Soldan, P.; Lee, E. P. F.; Wright, T. G. J. Phys. Chem. A 2002,106, 8619

(44) Wesendrup, R.; Kloo, L.; Schwerdtfeger, P. Int. J. Mass Spectrom.2000, 201, 17.

(45) Steinfeld, J. I.; Francisco, J. S.; Hase, W. L. Chemical Kinetics and Dynamics; Prentice Hall: Upper Saddle River, NJ, 1999.

(46) Kreevoy, M. M.; Truhlar, D. G. Transition State Theory. In InVestigation of Rates and Mechanisms of Reactions; Bernasconi, C. F., Ed.; Wiley: New York, 1986; Vol. 6, p 14.

(47) Levine, R. D.; Bernstein, R. B. Molecular Reaction Dynamics and Chemical ReactiVity; Oxford University Press: Oxford, 1987.

(48) Light, J. C. J. Chem. Phys. 1964, 40, 3221.

(49) Bunker, D. L. J. Chem. Phys. 1960, 32, 1001.

(50) Levine, I. N. Physical Chemistry; McGraw-Hill: New York, 1988.

(51) Gaydon, A. G. Dissociation Energies and Spectra of Diatomic Molecules, 2nd ed., revised ed.; Chapman and Hall: London, 1953.

(52) Huber, K.-P.; Herzberg, G. Constants of diatomic molecules; Van Nostrand Reinhold: New York, Toronto, 1979.

(53) Truhlar, D. G.; Garrett, B. C.; Klippenstein, S. J. J. Chem. Phys.1996, 100, 12771.

(54) Gilbert, S. C. S. Theory of unimolecular and recombination reactions; Blackwell: Cambridge, MA, 1990.

(55) Jobson, B. T.; Niki, H.; Yokouchi, Y.; Bottenheim, J.; Hopper, F.; Leaitch, R. J. Geophys. Res., [Atmos.] 1994, $99,23$.

(56) Givan, A.; Loewenscuss, A. J. Chem. Phys. 1980, 72, 3809.

(57) Gregg, A. H.; Hampson, G. C.; Jenkins, G. I.; Jones, P. L. F.; Sutton,L. E. Trans. Faraday Soc. 1937, $33,852$.

(58) Aylett, B. J. ComprehensiVe Inorganic Chemistry; Pergamon Press: Elmsford, NY, 1973; Vol. 3.

(59) Adams, D. M.; Hills, D. J. J. Chem. Soc., Dalton Trans. 1978, 776.

(60) Bondi, A. J. Phys. Chem. 1964, 68, 441. 